\title{
Herders' ecological knowledge and carnivore predation on livestock investigations in Makgadikgadi and Nxai national parks, Botswana
}

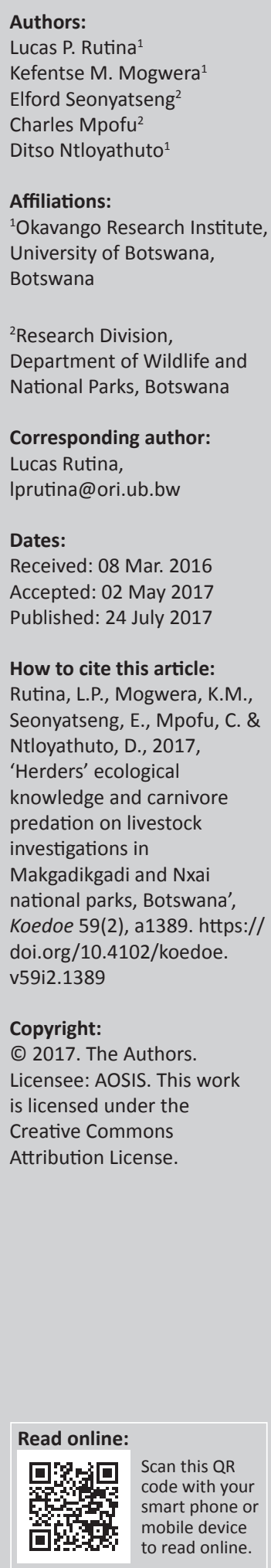

Botswana is one of the countries in Southern Africa that pay compensation for human properties damaged by wildlife. Before compensation is paid, a thorough investigation on determining wildlife species that have caused the damage is mandatory. Because of insufficient resources by the Department of Wildlife and National Parks, the initial investigation is carried out by herders. Three basic indicators are used to determine carnivore predation; sighting the carnivore at the kill, tracks of the predator and examining the carcasses. In this study, we tested herders' knowledge on the above three indicators. The study was conducted in a communal area around Makgadikgadi and Nxai national parks, Botswana, where the main activities practiced by the local communities is pastoral farming. In general, there was a significant association between reported and perceived incidents of predation for all carnivores at all distances from protected areas. Herders were able to identify the large carnivores visually. But they had difficulties in identifying carnivore tracks and kill characteristics. The results demonstrate the importance of involvement of local communities in human-wildlife conflict management. However, more education regarding identification of carnivore tracks and kill behaviour is needed for herders in the study area.

Conservation implications: Based on the results of this study, this calls for a change in the management of human-wildlife conflict (HWC) and administration of the compensation scheme. Decentralising HWC to local communities using existing government structures that exist at local level will not only supplement the inadequate resources by the Department of Wildlife and National Parks (DWNP) to effectively mitigate the problem, but also empower local communities' participation in wildlife management.

\section{Introduction}

Management of human-carnivore conflict using expert-based science (EBS) has been proven to be ineffective, and the conflicts have continued to have socio-economic implications on the livelihoods of pastoralists residing near protected areas globally (Goodrich et al. 2011; Inskip \& Zimmerman 2009). In response, pastoralists developed retaliatory behaviour by killing (both legal and illegal) or poisoning carnivores (Ogada et al. 2003), leading to the observed decline of carnivore populations. Information on distribution and intensity of human-carnivore conflict is essential in managing such conflicts around the world, and obtaining adequate information to come up with effective and efficient strategies requires extensive data on wildlife populations which is often insufficient in technical EBS (Gilchrist, Mallory \& Merkel 2005).Techniques involved in EBS are usually expensive and demanding in terms of inputs, thus complicating research (Anadón et al. 2009). However, it has been indicated that information from local knowledge and skills of communities could be of high quality at a relatively low cost (Hartwig 2009a). Despite appeals to integrate this knowledge in scientific research to enhance natural resource management, such efforts are seldom put into practice (Sutherland et al. 2013).

There is a widespread recognition that people residing in an area for long periods develop important and established relationships with and knowledge about those areas (Prado \& Murrieta 2015). Various terminologies have been proposed to describe this knowledge, such as local ecological knowledge (LEK) (Anadón et al. 2009), traditional ecological knowledge (TEK) (Phuthego \& Chanda 2004) and indigenous knowledge (IK) (Roba \& Oba 2009). Although many authors use this terminology interchangeably, Gilchrist et al. (2005) and Neagh et al. (2008) suggested that a distinction that comprehends the time scale from which this knowledge and skills has been acquired is required. The distinctions being that TEK and IK are more of knowledge and practices acquired through adaptive management, by an ethnic group through generations 
interacting with nature and is believed to be transferrable from one generation to another (Neagh et al. 2008), while LEK, on the contrary, describes the skills and practices gained and developed by an individual's annotations over his or her periods of interaction with nature, and this knowledge is not transferred from one generation to another (Gilchrist et al. 2005). In many studies, LEK is associated with the perception or skills possessed by individuals given their periods of interaction with nature. In this study, we assessed the competences of LEK possessed by livestock herders to investigate carnivore species that predate on livestock around Makgadikgadi and Nxai national parks. We define LEK in this study as the skills possessed by herders by virtue of experience from duties linking them with livestock depredation issues on a daily basis, and herders as individuals that are employed to look after livestock throughout the year, and this includes self-employed farmers. Herding activities included general husbandry of keeping livestock (taking livestock to pasture and water in the morning and bringing them back to the kraal [boma - a place where they are kept safe during the night]), looking for lost and unhealthy animals and reporting any problem concerning the keeping of the livestock to the owner (in case of employed herders).

Livestock farming in Botswana is very important because majority of the rural communities depend on it as a source of income and protein (Statistics Botswana 2009; Statistics Botswana 2013). As such, livestock production, especially cattle, plays a critical socio-economic role for farmers in Botswana. Depredation of livestock by carnivores therefore poses economic loss to farmers. Although the Botswana Wildlife Conservation and National Park Act of 1992 permits lethal control of wildlife in defence for human property damaged, Botswana is still one of the countries in Southern Africa that pay compensation for human properties damaged by wildlife as a measure to balance the trade-off between wildlife conservation and the impact of conflict they bring to the farming communities. Before compensation is paid, a thorough investigation on determining the wildlife species that has caused damage is mandatory. Because of insufficient resources by the Department of Wildlife and National Parks (DWNP), the initial investigation is carried out by herders. Necessary skills are needed to best find out which carnivore species is causing damage. Three basic indicators that are used to determine carnivore predation are sighting the carnivore at the kill (hereafter referred to as visual), tracks of the predator (hereafter referred to as tracks) and examining the carcasses (bite marks, body parts eaten and location of the carcasses, hereafter referred to as kill patterns).

Because information on livestock raiding carnivores in Botswana is currently insufficient (Hemson 2003; Valeix et al. 2012), this study used LEK possessed by herders to assess herders' ability to identify the carnivore species causing damage using the three indicators mentioned above and mapped their perceptions on magnitude and spatiotemporal patterns of large carnivore predation on livestock. One of the significant aspects of using LEK is to enhance the contribution of local people in policy decision-making in order to promote their participation in proper management of natural resources around them (Calamia 1999). The objectives of this study were to (1) compare carnivore predation reported to and confirmed by the DWNP (hereafter refer to as PAC) with reports made during interviews (hereafter referred to as LEK) for lion, leopard and wild dog; (2) compare the carnivore predation risk at cattle post (an area where the main activity is livestock farming) as determined by data collected by PAC and LEK and (3) assess herders' ability to identify carnivore species from visual photos, tracks and kill patterns.

\section{Materials and methods Study area}

The study was conducted in a communal area (CT 7) covering an area approximately $6543 \mathrm{~km}^{2}$ in the eastern side of Makgadikgadi (NG 52 and CT 9) and Nxai (NG 50) Pans National Parks, south of a wildlife management area (CT 1 and 2) and north of wildlife management area (CT 11), Botswana (Figure 1). A wildlife management area is an area designated for wildlife management, including sustainable utilisation of wildlife. The study area encompasses numerous cattle posts that practices subsistence mixed farming (arable and pastoral), with pastoral farming being the dominant farming type in the area. Human population in the area and surroundings has increased significantly, by almost $50 \%$ per annum and on average each cattle post had 10-20 members (CSO 2011). The study site composed of 63 cattle posts of which $9(14.2 \%)$ were within $10 \mathrm{~km}$ from protected areas (NEAR) and 54 (85.8\%) were beyond $10 \mathrm{~km}$ from protected areas (FAR). The study site falls within a semi-arid zone, lying between the $250 \mathrm{~mm}$ and $450 \mathrm{~mm}$ rainfall isohyets, with rainfall predominately between November and April (Shaw et al. 1997). However, during the study period, annual rainfall ranged from $338 \mathrm{~mm}$ to $412 \mathrm{~mm}$ (Statistic Botswana 2015). Dominant tree species in the area includes baobab (Adansonia digitata), some of which serve as land marks; leadwood (Combretum imberbe), silver terminalia (Terminalia sericea), mopane (Colophospermum mopane) and real fan palm (Hyphaene petersiana) (Brooks \& Maude 2010). Most of wildlife species are residents inside the parks, but several species seasonally migrate in and out in response to fluctuation of resources, especially surface water and forage. Herbivore species include zebra (Equus quagga), springbok (Antidorcas marsupialis), blue wildebeest (Connochaetes taurinus) and gemsbok (Oryx gazella) (DWNP 2012; Kgathi \& Kalikawe 1993). Large carnivores include the African lion (Panthera leo), leopard (Panthera pardus), spotted hyena (Crocuta crocuta), cheetah (Acinonyx jubatus) and African wild dog (Lycaon pictus) (Hemson 2003; Rutina et al. 2015; Valeix et al. 2012).

In the last century, the Basarwa people were the dominant people in the area, depending mainly on hunting and gathering of wild resources (Ferrar 1995). However, around the 1930s when technology for accessing groundwater in the area improved, other tribes and their livestock settled 


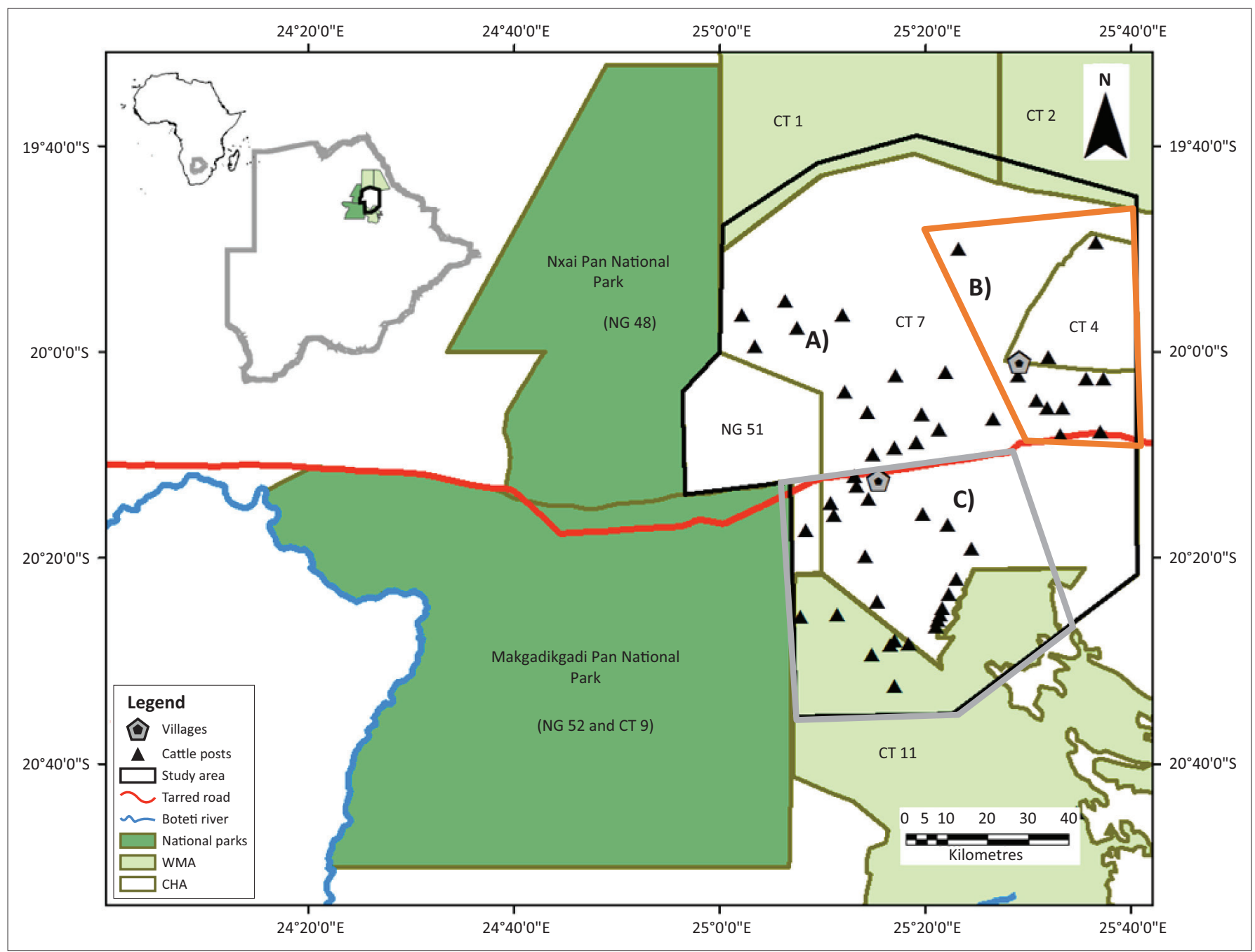

Source: Mogwera 2017 (unpublished)

The sections were categorised in relative to the protected areas with Section A near Nxai National Park, Section B Makgadikgadi National Park and Section C far away from both parks.

FIGURE 1: Map of the study area showing the communal area (CT 7) in relation to protected areas (national parks [Nxai and Makgadikgadi] and wildlife management areas [CT 1, CT 2 and CT 11]) and the three section division as used to group herders during the workshop. Section A is Gweta north, B is Gweta south and C is Nogatshaa.

in the area. The arrival of these other ethnic groups, mainly Bakalanga, Banabiya and Bangwato, in the area diluted the Basarwa TEK and IK. According to DWNP (DWNP, personal communication), the eastern boundary of Makgadikgadi Pans National Park has been a centre of controversy since its proclamation in 1971 because people believed it was moved closer to them, thus taking their grazing land and crop fields. This has led to pastoralist's argument that the eastern park boundary is too close to them. In addition, this has led to cattle moving and grazing in protected areas and wildlife management. The erection of the carnivore proof fence in the western boundary of the park, along the Boteti River could have shifted wildlife movements towards the study area especially during the wet season when water is available.

\section{Data collection and analysis}

\section{Incidents of carnivore predation on livestock}

Data on incidents of carnivore predation on livestock were obtained from the DWNP. The incidents are investigated and documented by the department's Problem Animal Control (PAC) unit for the purpose of financially compensating for damage by species that are considered to be too dangerous for farmers to confront or chase away from their property, or those that are considered to be of high protection priority. As such the records enable research on the spatial and temporal dynamics of human-wildlife conflict (HWC) in the country (Schiess-Meier et al. 2007). Details involving type and number of livestock killed, predator species involved, date and place of attacks (name of cattle post) were captured. Five years' PAC data from 2008 to 2012 were considered for analysis on the premise that more data improve accuracy of results. The reports lacked precise locations such as global positioning system (GPS) coordinates of the actual location of damage, thereby compelling data to be analysed at the cattle post level. Cattle posts were visited with the help of local community assistants, and their point locations were recorded using a handheld GPS device.

\section{Herders' local ecological knowledge}

Because it is important to gather data from people who have lived in the area long enough, and who have been closely associated with issues concerning livestock depredations, 62 herders, 51 (82\%) from cattle posts far from protected areas 
and $11(18 \%)$ from cattle posts near protected areas were randomly selected from the list of farmers who reported carnivore predation on their livestock to the DWNP. Livestock herders (e.g. employed or owners) were targeted because they relatively spend more time with livestock. According to Roba and Oba (2009), livestock herder indicators are appropriate for pastoral farming because they are closely connected to human livelihoods as opposed to ecologists. A semi-structured questionnaire survey was conducted on the selected herders. The main objective of these interviews was to gain information regarding the herders' understanding of wildlife-livestock interaction, with a focus on carnivore interactions with livestock (predation) and other human activities. Specific objective was to assess how long the herders have been in the area, how many livestock did they lose because of each of the three carnivores (lion, leopard and wild dog) and how do they perceive predation risk (measured in terms of livestock lost to each carnivore per month). Out of the 62 herders interviewed, $40(65 \%)$ were self-employed (owners) and 22 (35\%) were employed herders. All employed herders were males ranging between 25 and 40 years of age. Of the self-employed herders, 18 (46\%) were females and 22 $(54 \%)$ were males. Out of the 62 herders interviewed, 30 (48\%), 10 females and 20 males were invited for a workshop to map carnivore predation hotspots. Selection was based on their experience and period stayed in the area. The selection also considered the spatial distribution of the cattle posts. The study area was divided into three sections (northern, central and southern). Ten herders were selected from each section. Working in their sections, participants provided information based on their own experience or knowledge gained from other community residents about carnivore predation on livestock risk per each cattle post in their section. All information was recorded on the paper maps provided, by categorising cattle posts into one of the three risk categories (low $=1$, medium $=2$ and high $=3$ ) for each carnivore. Risk categories were based on the results from the interviews. Herders considered predation incidents of zero to three per month as low risk, four to six as moderate and greater than six as high.

To assess ecological knowledge of herders to identify carnivores using the three indicators used in compensation investigations, the 30 herders invited to the workshop were shown picture cards of carnivores and were asked to identify them (Figure 2). Similarly, herders were asked to identify tracks and examine carcasses from picture cards (Figure 2).

\section{Data analysis}

We used $\chi^{2}$ test to know whether there was a significant association between data obtained from confirmed predation incidents and data obtained from interviews, given the distance from protected areas and carnivore species. We also used the $\chi^{2}$ test to determine whether there were significant differences between the frequencies of herders who identified carnivores correctly to those who did not.

Kruskal-Wallis test with Dunn-Bonferroni post hoc test was performed to test the hypothesis that risk categories of the three carnivores from LEK and PAC were the same across the distances from protected areas. We further calculated conditional probability that both LEK and PAC data will place a cattle post in the same category. The conditional probability was calculated as the chances that both LEK and PAC will place a cattle post in the same category divided by the total possible outcomes. Finally, we use frequencies (percentages) to assess the ability of herders to identify carnivore species using the three indicators used in carnivore predation investigations by DWNP.

\section{Results}

\section{Incidents of carnivore predation on livestock}

Comparing data obtained from confirmed predation incidents and data obtained from interviews, there was no significant association between PAC and LEK incidence for all carnivores at all distances from protected areas $\left(\chi^{2}\right.$ test, $p>0.05$ for all tests). Both PAC and LEK showed that more than $60 \%, 75 \%$ and $80 \%$ of the cattle posts in the study area experienced low predation by lion, leopard and wild dog, respectively. However, the association between PAC and LEK for all the carnivores was distance specific. Lion PAC incidents for cattle posts near protected areas were significantly higher than LEK incidents, while there was no significant difference between PAC and LEK for cattle posts far from protected areas (Figure 3a). For leopard and wild dog, LEK incidents were higher than PAC incidents for all the distance from protected areas (Figure $3 b$ and $3 c$, respectively). Although no PAC reports were available in the study area because the species is not compensated, LEK incidents showed that spotted hyena caused more damage than the three reported species, especially on cattle posts far from protected areas (Figure 4).
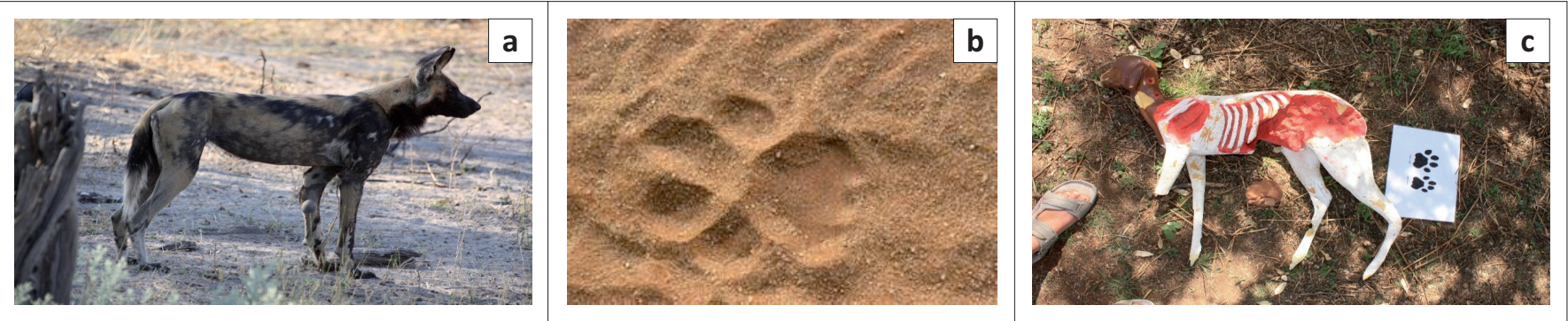

Source: ( $a$ and b) Photos taken by Lucas Rutina and (c) from Cheetah Conservation Fund, Otjiwarongo, Namibia

FIGURE 2: Examples of cards used to assess herders' skills to identify carnivores. (a) Visual, (b) track and (c) kill pattern. 

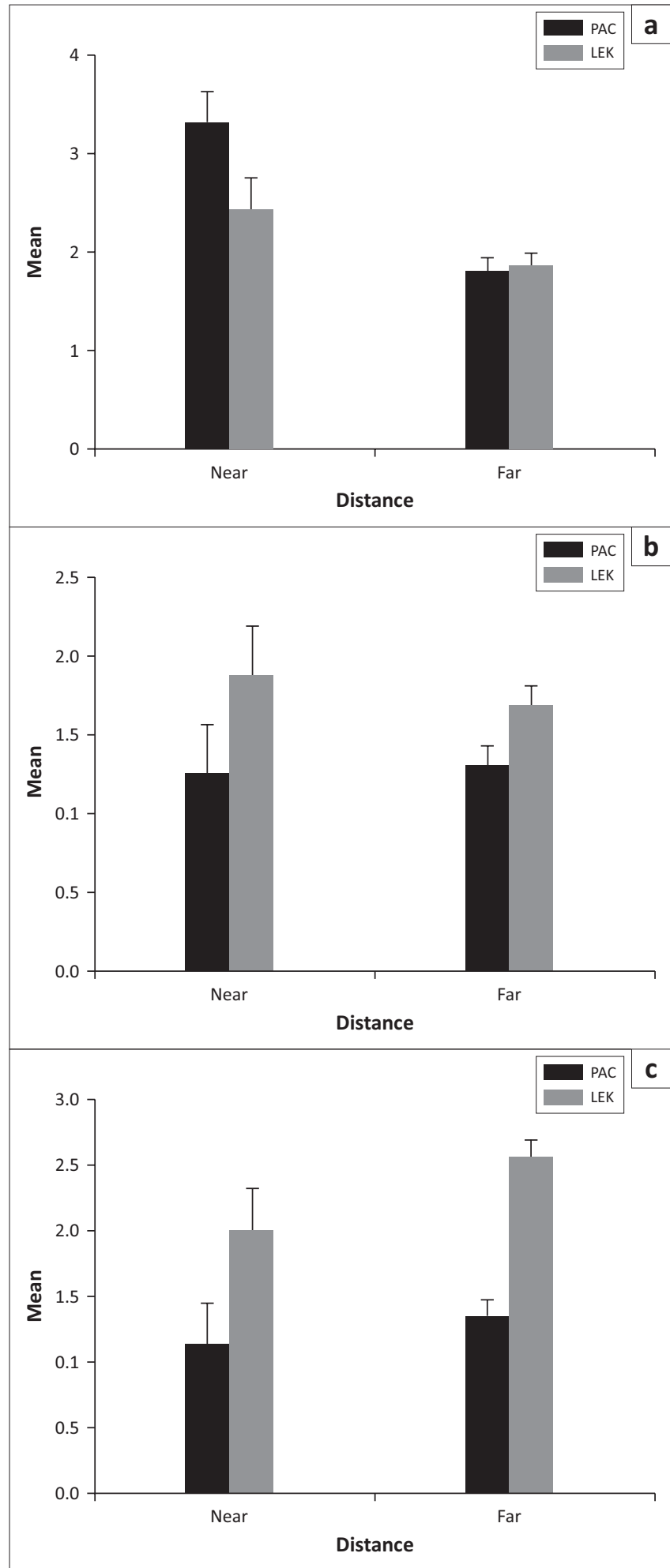

FIGURE 3: Comparison of carnivore predation on livestock incidents between Department of Wildlife and National Parks-confirmed incidents (Problem Animal Control) and herders interviewed (local ecological knowledge). (a) Lion, (b) leopard and (c) wild dog.

\section{Carnivore predation risk}

After standardising reports to predation risk categories, a Kruskal-Wallis test showed that there was a statistically significant difference in lion predation risk categories between PAC and LEK for cattle posts beyond $10 \mathrm{~km}$ from protected areas (FAR) $\left[\chi^{2}(1)=14.591, p<0.001\right]$ (Figure 4a).
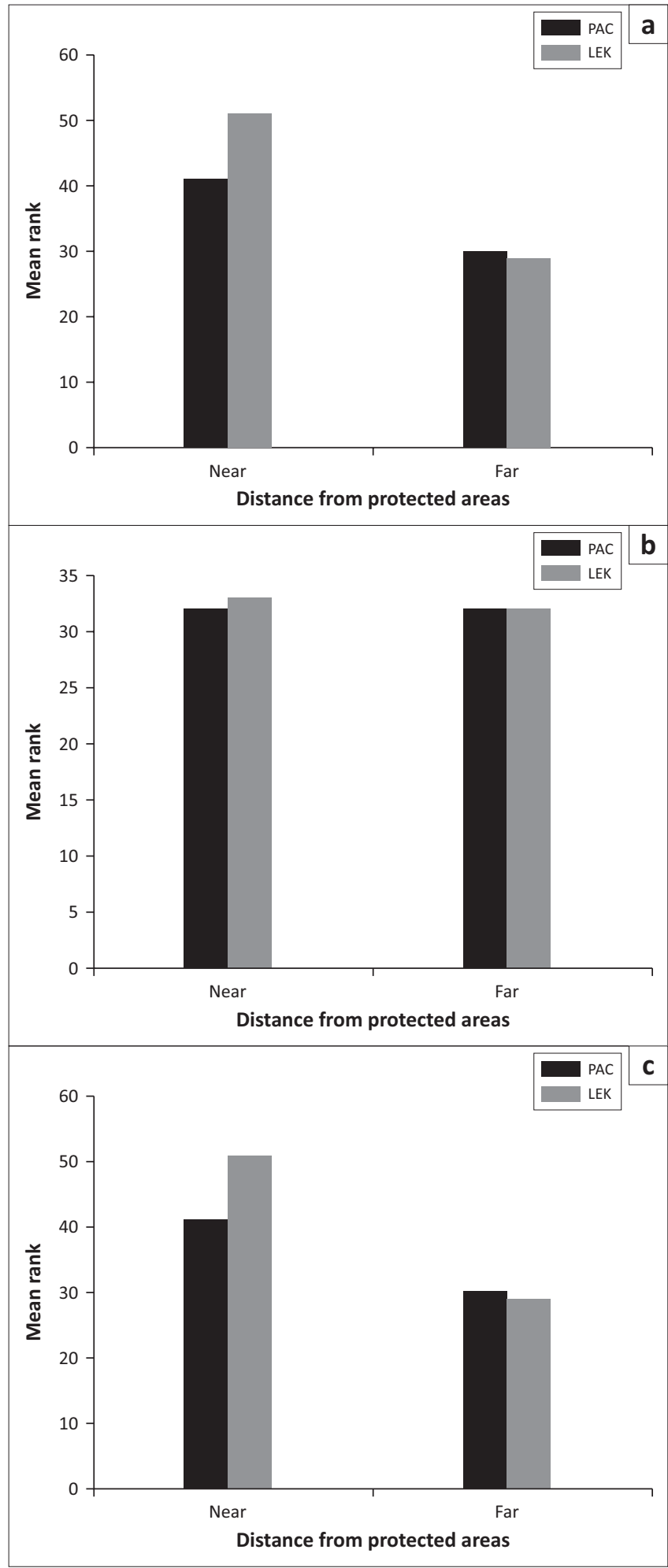

FIGURE 4: Comparison of carnivore predation in livestock risk areas between Department of Wildlife and National Parks-confirmed incidents (Problem Animal Control) and herders interviewed (local ecological knowledge). (a) Lion, (b) leopard and (c) wild dog.

The Dunn-Bonferroni post hoc test indicated that the difference was significant for cattle posts near from protected areas (test statistic $=14.44, p=0.004$ ) but no significant difference was found for cattle posts far protected areas (test statistic $=-9.11, p=0.453$ ) (Figure 4a). Both leopard and wild dog predation risk categories between PAC and LEK for all cattle posts were not statistically different (Kruskal-Wallis 
test, $p>0.05)$. Predation risk categories between PAC and LEK for cattle posts beyond $10 \mathrm{~km}$ from protected areas were not statistically different (Kruskal-Wallis test, $p>0.05$ ) for all three carnivores (Figure $4 \mathrm{a}, \mathrm{b}$ and $\mathrm{c}$ ).

The probability that both PAC and LEK will categorise a cattle post in the same predation risk category for lion was $70 \%$ and $56 \%$ for cattle posts FAR and NEAR protected areas, respectively. For leopard, the probability that both PAC and LEK will categorise a cattle post in the same predation risk category was $67 \%$ and $56 \%$ for cattle posts FAR and NEAR protected areas, respectively. For wild dog, the probability that both PAC and LEK will categorise a cattle post in the same predation risk category was $63 \%$ and $78 \%$ for cattle posts FAR and NEAR protected areas, respectively.

\section{Identification of carnivore species}

In general, herders were able to identify the large carnivores visually: NEAR $-76 \%$ and FAR - 75\% (Figure 5). By contrast, herders had difficulties in identifying carnivore tracks and kill characteristics (Tracks: near $=35 \%$, far $=63 \%$; kill characteristics: near $=35 \%$, far $=34 \%$, Figure 5). Results from the investigation diaries suggest that for all the cases where herders used their ecological knowledge to identify the carnivore that had caused the damage in $82 \%, 67 \%$ and $100 \%$ of the cases are approved by DWNP for lion, wild dog and leopard, respectively.

\section{Discussion}

Although LEK is not commonly used in mapping the spatial and temporal patterns of human-carnivore conflict, the results of this study show that confirmed carnivore predation incidents and reports gathered through interviewing herders did not significantly differ for all the three carnivores and distances from protected areas. This shows that carnivore predation information collected through LEK and the standard protocols used by DWNP were complementary. Similar results have been observed with other species such as tortoise distribution in south-eastern Spain (Anadón et al. 2009), fish and fisheries management in the Beaufort Sea, Canada (Hartwig 2009b), southern Mexico (Espinoza-Tenorio et al. 2013), south-eastern Brazil (Teixeira et al. 2013) and wild mammals in northern Gonarezhou National Park, Zimbabwe (Gandiwa 2012). The results further show that both LEK and PAC data were in agreement over the fact that lion predation decreases with increasing distance from protected areas (Figure 3a) and leopard incidents were evenly distributed throughout the study area (Figure 3b). Contrary to the other two carnivores, there was disagreement between LEK and PAC data on the distribution of wild dog predation incidents in the study area, with PAC data indicating that wild dog predation incidents were evenly distributed and LEK indicating that wild dog predation incidents increased with decreasing distance from protected areas. The results are partly comparable to the findings that stronger carnivores such as lion are more problematic in the periphery of protected areas, while outcompeted smaller ones are forced to forage deeper into human-dominated landscapes (Gusset et al. 2009; Mogwera \& Rutina 2015; Rutina et al. 2015). It is also apparent that during the dry season, carnivore problems are more pronounced, particularly because the preferred wild prey has migrated to their dry season habitats, thus leaving livestock in high abundance and as alternative prey (Valeix et al. 2012).

In general, LEK and PAC were in agreement in categorising cattle posts for carnivore predation risk areas. In addition, the study shows that the chances that LEK predictions for carnivore predation risk to be similar to confirmed incidents were high for both the three carnivore at all distances from protected areas. This is consistent with other studies that showed LEK information complement scientific information in mapping environmental hazards (Anh, Phong \& Mulenga 2014; Raungratanaamporn \& Pakdeeburee 2014; Udmale, Ichikawa \& Manandhar 2014), fisheries (Silvano \& Begossi 2012), natural resource management (Gilchrist et al. 2005; Ruddle \& Calamia 1999), environmental planning (Kujala et al. 2013), natural resources research (Anadón et al. 2009; Gandiwa 2012; Silvano \& Begossi 2012) and HWC hotspots (Calamia 1999; Hartwig 2009a; Rutina et al. 2015; Strindberg et al. 2007). This significant contribution of LEK to map carnivore predation areas indicates the potential impotence of LEK in HWC management in the region.

We expected that that herders, having grown up with wildlife could easily identify carnivores visually and their tracks. However, we found that herders can identify large carnivore species visually but had difficulties in identifying carnivore tracks and kills patterns. This could be attributed to the current herding practises that are carried in the study area. Gontse et al. (2012) found that because of the paying schedule from the Department of Labour Affairs, farmers are not able to pay herders for all the activities involved in the practice of herding. As such, herders are now taking livestock to water points and kraal that arrive back during the afternoon (Gontse et al. 2012; Rutina et al. 2015). Contrary to the results of this study, information from the DWNP investigation diaries suggests confirmed $82 \%$ of lion-related incidents, $67 \%$ of wild dog-related incidents and $100 \%$ of leopard-related incidents identified by herders who used their ecological knowledge. Furthermore, data from diaries suggest that herders use tracks and/or patterns of kill to identify carnivores causing damage. As we have shown above, herders had difficulties in identifying carnivore tracks and kill patterns (Figure 5). We thus recommend that more education regarding identification of carnivore tracks and kill behaviour is needed for herders in the study area. Nevertheless, the results of the study show that most of the carnivore predation on livestock information was from LEK (e.g. number of cases [Figure 3], risk areas [Figure 4] and visual identification of carnivores [Figure 5]) mentioned by the herders corresponded with information obtained from scientifically recognised methods.

Lack of resources by the DWNP to mitigate and attend to carnivore predation on livestock in the study area have 

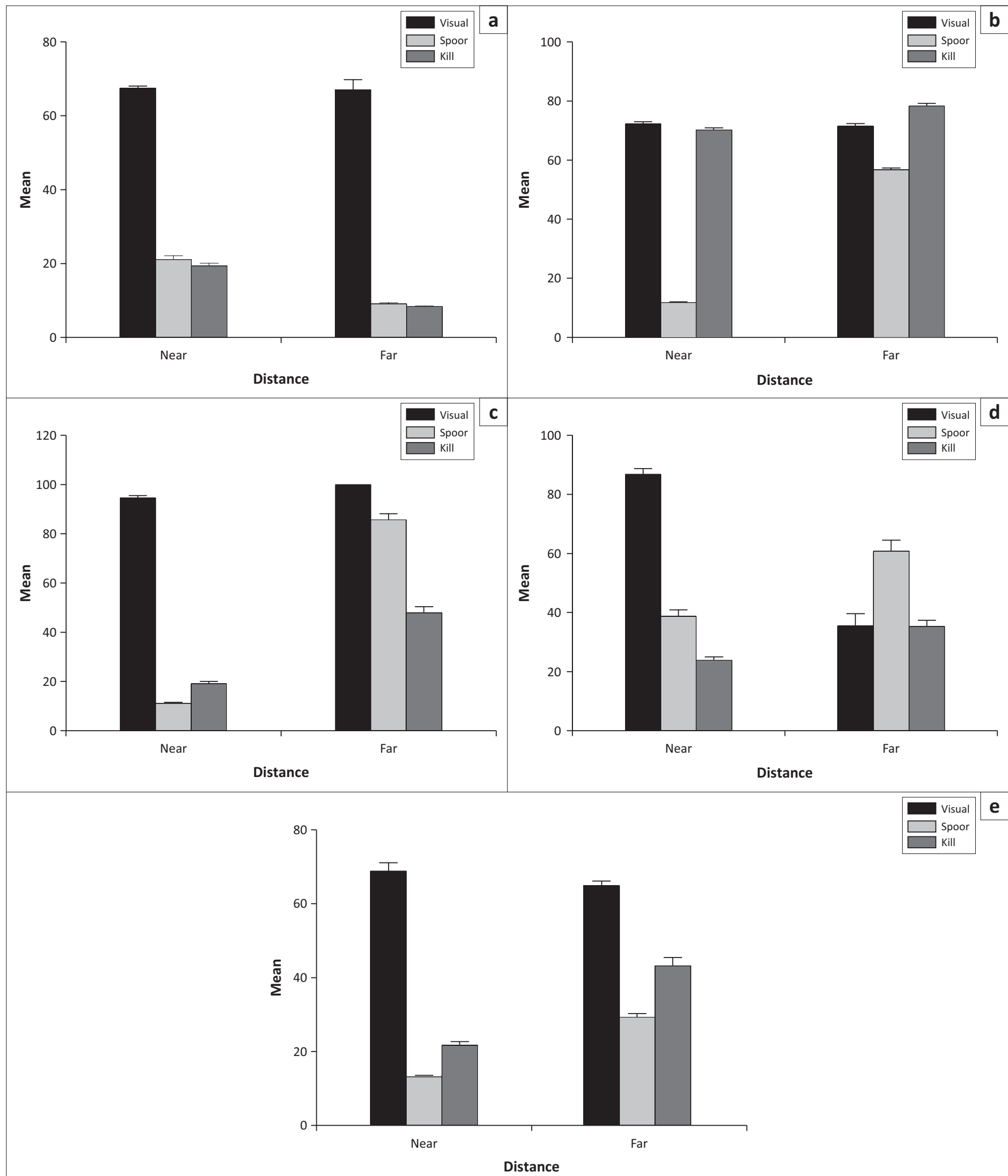

FIGURE 5: Percentage of herders who identified carnivore species correctly from cards. (a) Cheetah, (b) leopard, (c) lion, (d) spotted hyena and (e) wild dog.

been suggested as one factor contributing to humancarnivore conflict in the study area (Gontse et al. 2012; Hemson 2003; Hemson et al. 2009; Rutina et al. 2015; Valeix et al. 2012). Because of the inadequate resources by DWNP, most of HWC mitigation measures are conducted at a large scale and use a 'one size fits all' strategy. Despite different opinions among scientists and policy-makers as to the use of LEK in natural resource management (see Mclain et al. 2013) and given the complexity and nature of HWC, mitigation strategies need to be area and species specific. The difficulties are mostly because of lack of mutual understanding among stakeholders, including local 
communities, towards wildlife management approaches, and this undermines the effectiveness of integrating LEK in HWC. Coordination among government, communities and scientists has been suggested as the best strategy to manage natural resources (Espinoza-Tenorio et al. 2013; Gilchrist et al. 2005; Mclain et al. 2013; Neagh et al. 2008; Phuthego \& Chanda 2004). Based on the results of this study, we argue that decentralising HWC to local communities using existing government structures that exist at local level, such as district conservation committees, village development committees and village farmer committees will improve the problem. This will not only supplement the inadequate resources by the DWNP to effectively mitigate the problem, but also empower local communities in wildlife management and tap on the LEK the community have. The implementation of community-based natural resources management goes along training communities to collect data for monitoring purposes and inform government strategies using a Management-Oriented Monitoring System (MOMS). The use of MOMS in carnivore predation investigations will significantly improve information on management of human-carnivore conflict. This should include the recognition that in order to increase the effectiveness of reducing or mitigating carnivore predation on livestock, communities should play important roles by applying their LEK understanding of the spatiotemporal dynamics of carnivore predation rather than focusing on increasing DWNP capability to mitigate HWC.

Over the past 10 years, southern African governments have been engaged in creating Transfrontier Conservation Areas, consisting of a mosaic of different land uses. Within this mosaic agricultural landscapes play an important role as habitat and corridors for wide-ranging wildlife, such as large carnivores, because the sizes of most protected wildlife areas are not large enough to adequately accommodate their home ranges. Our study site forms part of the Kavango-Zambezi Transfrontier Conservation Area (KAZA TFCA), a conservation area covering part of Angola, Botswana, Namibia, Zambia and Zimbabwe. Both countries, through revision of their National Biodiversity Strategy and Action Plans (NBSAPs) to align them with CBD 2015 goals and 2020 Aichi targets, recognise that HWC hinders the promotion of integration between biodiversity conservation and human well-being and have prioritised HWC as priority areas that need to be addressed in their Integrated Development Plans (IDPs) for their KAZA TFCA components. The results of our study suggest that involving local communities in managing HWC could help the KAZA TFCA mandate to be realised.

\section{Conclusion}

The results of the study showed that both PAC and LEK information were complementary in reporting incidents of carnivore predation on livestock and categorising cattle posts for carnivore predation risk for the three carnivores studied. This calls for involvement of local communities in carnivore predation investigations and management. This will not only complement the shortage resources by government to manage conflict, but also reduce the spatial scale at which conflict management is conducted. This can be done by decentralising HWC management to local communities using government structures that exist at local level. However, herders had difficulties in identifying carnivore tracks and kill patterns. This could be due to partly poor pictures used because information from the DWNP investigation diaries suggests that almost all confirmed incidents were identified by herders using tracks and/or patterns of kill.

\section{Acknowledgements}

We acknowledge the Southern Africa Science Service Centre for Climate Change and Adaptive Land-use (SASSCAL) and the University of Botswana internal funding for supporting this project. The Department of Wildlife and National Parks (Serowe and Nata offices) provided reported and confirmed data used in this study. Gaoratwe and Lungisane from DWNP Nata office helped the research team in identifying cattleposts. Thebe, Sekotswe and Toro, research assistants from the Okavango research institute, and Makgetho and Moathodi, community assistants, helped the researcher in field data collection.

\section{Competing interests}

The authors declare that they have no financial or personal relationships that may have inappropriately influenced them in writing this article.

\section{Authors' contributions}

L.P.R. was the principal investigator for the project, designed the project objectives, coordinated herders' workshops, performed data analysis and write up. K.M.M. and D.N. conducted herders' interviews, led group discussions during the herders' workshops and contributed to the write up. E.S. and C.M. collected, collated and analysed carnivore predation on livestock reports from DWNP, participated in the herders' workshops and write up.

\section{References}

Anadón, J.D., Giménez, A., Ballestar, R. \& Pérez, I., 2009, 'Evaluation of local ecological knowledge as a method for collecting extensive data on animal abundance', Conservation Biology: The Journal of the Society for Conservation Biology 23(3), 617-625. https://doi.org/10.1111/j.1523-1739.2008.01145.x

Anh, T.T., Phong, T.V.G. \& Mulenga, M., 2014, 'Community consultation for climate resilient housing: A comparative case study in Vietnam', International Journal of Disaster Risk Reduction 10(PA), 201-212. https://doi.org/10.1016/j. ijdrr.2014.09.012

Brooks, C. \& Maude, G., 2010, 'Wildlife resources and human wildlife conflict', in Center for Applied Resesearch (eds.), Makgadikgadi framework management plan, p. 161, Department of Environmental Affairs, Botswana.

Calamia, M., 1999, 'A methodology for incorporating traditional ecological knowledge with geographic information systems for marine resource management in the Pacific', Resource Management and Knowledge Information 16, 2-12.

DWNP, 2012, Aerial Census of Animals in Botswana: 2012 Dry. Season, Department of Wildlife and National Parks, Gaborone.

Espinoza-Tenorio, A., Wolff, M., Espejel, I. \& Montaño-Moctezuma, G., 2013 'Using traditional ecological knowledge to improve holistic fisheries management: Transdisciplinary modeling of a lagoon ecosystem of Southern Mexico', Ecology and Society 18(2), (6), 1-18 https://doi.org/10.5751/ESMexico', Ecology
$05369-180206$ 
Ferrar, T., 1995, Makgadikgadi/Nxai Pan management plan, Department of Wildlife and National Parks, Gaborone.

Gandiwa, E., 2012, 'Local knowledge and perceptions of animal population abundances by communities adjacent to the northern Gonarezhou National Park, Zimbabwe', Tropical Conservation Science 5(3) 255-269. https://doi. org/10.1177/194008291200500303

Gilchrist, G., Mallory, M. \& Merkel, F., 2005, 'Can local ecological knowledge contribute to wildlife management? Case studies of migratory birds', Ecology and Society 10(1), 12. https://doi.org/10.5751/ES-01275-100120

Gontse, K., Mogwera, K., Mmusi, M. \& Mhale, K., 2012, An investigatiojn of factors influencing persistance of human-carnivore conflict in western Tutume subdistrict, Botswana, Winter Course Report, University of Botswana, Maun.

Goodrich, J.M., Seryodkin, I., Miquelle, D.G. \& Bereznuk, S.L., 2011. Conflicts between Amur (Siberian) tigers and humans in the Russian Far East. Biological Conservation 144, 584-592.

Gusset, M., Swarner, M.J., Mponwane, L., Keletile, K. \& McNutt, J.W., 2009, 'Humanwildlife conflict in northern Botswana: livestock predation by Endangered African wild dog Lycaon pictus and other carnivores', Oryx 43(1), 67-72. https://doi. org/10.1017/S0030605308990475

Hartwig, L., 2009a, Mapping traditional knowledge related to the identification of ecologically and biologically significant areas in the Beaufort Sea, Canadian ecologically and biologically significant areas in the
Manuscript Report of Fisheries and Aquatic Sciences.

Hartwig, L., 2009b, 'Mapping traditional knowledge related to the identification of ecologically and biologically significant areas in the Beaufort Sea', Canadian Manuscript Report of Fisheries and Aquatic Sciences 2895, 31.

Hemson, G., 2003, 'The ecology and conservation of lions: Human-wildlife conflict in semi-arid Botswana', PhD thesis.Lady Magret Hall, Univrsity of Oxford.

Hemson, G., Maclennan, S., Mills, G., Johnson, P. \& Macdonald, D., 2009, 'Community, lions, livestock and money: A spatial and social analysis of attitudes to wildlife and the conservation value of tourism in a human-carnivore conflict in Botswana', Biological Conservation 142, 2718-2725. https://doi.org/10.1016/j. biocon.2009.06.024

Inskip, C. \& Zimmermann, A., 2009, 'Human-felid conflict: a review of patterns and priorities worldwide', Oryx 43(1), 18-34.

Kgathi, D.K. \& Kalikawe, M.C., 1993, 'Seasonal distribution of zebra and wildebeest in Makgadikgadi Pans Game Reserve, Botswana', African Journal of Ecology 31 210-219. https://doi.org/10.1111/j.1365-2028.1993.tb00534.x

Kujala, H., Moilanen, A., Araújo, M.B. \& Cabeza, M., 2013, 'Conservation planning with uncertain climate change projections', PLOS One 8(2), 1-12. https://doi. org/10.1371/journal.pone.0053315

Mclain, R., Poe, M., Cerveny, L., Besser, D. \& Blahna, D., 2013, 'Making sense of human ecology mapping: An overview of approaches to integrating socio-spatial data into environmental planning', Human Ecology 41(1), 17. https://doi. data into environmental planning

Mogwera, K. \& Rutina, L., 2015, 'Predicting spatio-temporal distribution of humancarnivore conflict in response to environmental factors in Makgadikgadi agroecosystem, Northern Botswana', in L. Rutina, M. Nthomiwa \& D. Ntloyathuto (eds.), Botswana symposium on wetlands and wildlife 2015, pp. 160-171, University of Botswana, Maun.

Neagh, L., Ireland, N., Quinn, R.J., Donnelly, D.J. \& Cooper, J.A.G., 2008, 'Accurate mental maps as an aspect of local ecological knowledge (LEK): A case study from', Ecology and Society 13(1), 24

Ogada, M.O., Woodroffe, R., Oguge, N.O. \& Frank, L.G., 2003, 'Limiting depredation by African Carnivores: The role of livestock husbandry', Conservation Biology 17 1521-1530. https://doi.org/10.1111/j.1523-1739.2003.00061.x

Phuthego, T. \& Chanda, R., 2004, 'Traditional ecological knowledge and communitybased natural resource management: Lessons from a Botswana wildlife management area', Applied Geography 24(1), 57-76. https://doi.org/10.1016/j. apgeog.2003.10.001
Prado, H.M. \& Murrieta, R.S., 2015, 'Ethnology in perception: The origins, interfaces and current trends of a growing field', Sao Paulo XViii(4), 133-154.

Raungratanaamporn, I. \& Pakdeeburee, P., 2014, 'Government-communities collaboration in disaster management activity : Investigation in the current flood disaster management policy in Thailand', Procedia Environmental Sciences 20 658-667. https://doi.org/10.1016/j.proenv.2014.03.079

Roba, H.G. \& Oba, G., 2009, 'Community participatory landscape classification and biodiversity assessment and monitoring of grazing lands in northern Kenya', Journal of Environmental Management 90, 673-682. https://doi.org/10.1016/j. jenvman.2007.12.017

Ruddle, K. \& Calamia, M.A., 1999, 'A methodology for incorporating traditional ecological knowledge with geographic information systems for marine resource management in the Pacific, SPC Traditional Marine Resource Management and Knowledge Information Bulletin 10, 2-12.

Rutina, L., Seonyatseng, E., Mpofu, C. \& Mogwera, K., 2015, Interactive influence of carnivore foraging behavior and farmers' perception on human carnivore conflict in western Tutume sub-district, Botswana, Technical Report, Okavango Research Institute, University of Botswana, Maun.

Schiess-Meier, M., Ramsauer, S., Gabanapelo, T. \& König, B., 2007, 'Livestock predation - Insights from problem animal control registers in Botswana' Journal of Wildlife Management 71(4), 1267-1274. https://doi.org/10.2193/ 2006-177

Shaw, P.A., Stokes, S., Thomas, D.S.G., Davies, F.B.M. \& Holmgren, K., 1997, 'Palaeoecology and age of a quaternary high lake level in the Makgadikgadi Basin of the Middle Kalahari, Botswana', South African Journal of Science 93(6), Basin of the $273-276$.

Silvano, R.A.M. \& Begossi, A., 2012, 'Fishermen's local ecological knowledge on Southeastern Brazilian coastal fishes: Contributions to research, conservation, and management', Neotropical Ichthyology 10(1), 133-147. https://doi. and management', Neotropical It chth

Statistics Botswana, 2009, Population census, Botswana Government Printers, Gaborone.

Statistics Botswana, 2012, Agricltural sector Report, Botswana Government Printers, Gaborone.

Statistics Botswana, 2013, Agricltural sector Report, Botswana Government Printers, Gaborone.

Statistics Botswana, 2015, Agricltural sector Report, Botswana Government Printers, Gaborone.

Strindberg, S., Johnson, A.A.H., Hallam, C., Rasphone, A., Van Der Helm, F., Xiongyiadang, P. \& Sisavath, P., 2007, 'Recommendations for monitoring landscape species in the Nam Kading National Protected Area', Wildlife Conservation Society (WCS) and the Integrated Ecosystem and Wildlife Management Project(IEWMP) January-20(October 2015), 1-59.

Sutherland, W.J., Gardner, T.A., Haider, L.J. \& Dicks, L.V., 2013, 'How can local and traditional knowledge be effectively incorporated into international assessments?', Oryx 48(1), 1-2. https://doi.org/10.1017/S0030605313001543

Teixeira, J.B., Martins, A.S., Pinheiro, H.T., Secchin, N.A., Leão de Moura, R. \& Bastos, A.C., 2013, 'Traditional ecological knowledge and the mapping of benthic marine habitats', Journal of Environmental Management 115, 241-250. https://doi. org/10.1016/j.jenvman.2012.11.020

Udmale, P., Ichikawa, Y. \& Manandhar, S., 2014, 'Farmers $\mathrm{a} €^{\mathrm{TM}}$ perception of drought impacts, local adaptation and administrative mitigation measures in Maharashtra', International Journal of Disaster Risk Reduction 10, 250-269. https://doi.org/10.1016/j.ijdrr.2014.09.011

Valeix, M., Hemson, G., Loveridge, A.J., Mills, G. \& Macdonald, D.W., 2012, 'Behavioural adjustments of a large carnivore to access secondary prey in a human-dominated landscape', Journal of Applied Ecology 49, 73-81. https://doi.org/10.1111/j 1365-2664.2011.02099.x 